\title{
Effect of Metabolic Syndrome on Depression in Mice
}

\author{
Aniruddha Mukherjee ${ }^{1}$, Kalyan K Sen ${ }^{1}$ and Sugato Banerjee ${ }^{2 *}$ \\ ${ }^{1}$ Department of Pharmacology, Gupta College of Technological Sciences, Asansol West Bengal, INDIA. \\ ${ }^{2}$ Department of Pharmaceutical Sciences and Technology, Birla Institute of Technology, Mesra, Ranchi, INDIA.
}

\begin{abstract}
Metabolic syndrome (MetS) is associated with high blood glucose, insulin resistance, dyslipidemia, central obesity, and hypertension. There is clinical evidence of the coexistence of depression and MetS, however, pathways associating these diseases are far from clear. In the present study, we evaluate and determine the pathogenesis of depression in MetS animals. Methods: Diet induced (High-fat diet long with 20\% fructose water; HFHC diet for 4 weeks) MetS was developed in swiss albino mice. Fasting blood glucose levels, Lipids and blood pressure (BP) was measured in these animals. Development of depression in these animals was determined using forced swim and tail suspension tests. This was followed by measurement of GABA, dopamine, serotonin and norepinephrine levels in these animals. We also evaluated the effect of various antidepressants, on MetS associated depression. Results: MetS was induced using high fat and high carbohydrate (HFHC) diet in Swiss albino mice with high fasting blood glucose levels ( $>250 \mathrm{mg} / \mathrm{dl})$, significantly increased LDL $(p<0.001)$ and triglyceride $(p<0.01)$ and reduced HDL levels $(p<0.05)$ and significant increase in systolic BP; $p<0.001)$ compared to normal controls. MetS animals showed signs of depression with significantly higher $(\mathrm{p}<0.001)$ immobility time in forced swim and tail suspension tests. These animals showed significantly lower corticohippocampal norepinephrine (NE) levels $(p<0.01)$ compared to controls. Nortryptaline, showed a dose dependent decrease in immobility time in MetS animals $(p<0.001)$ in both forced swim and tail suspension tests thus reversing MetS induced depression. Conclusion: The above results suggest that MetS may lead to depression in mice which is primarily mediated by NE system.
\end{abstract}

Key words: Depression, Dopamine, Metabolic syndrome, Norepinephrine, Obesity, Serotonin, Type 2 Diabetes.

\section{INTRODUCTION}

Major depressive disorder (MDD), a debilitating disorder has a high prevalence of 16.2\%. ${ }^{1}$ Current anti-depressants reverse depression only in one-third of the affected patients. $^{2}$ Another major disease, metabolic syndrome may increase the risk of cardiovascular complications, obesity, and diabetes. Metabolic syndrome (MetS) is a conglomerate of interconnected disorders that includes insulin resistance in association with obesity, dyslipidemia and hypertension. ${ }^{3}$ Almost $25 \%$ of the adults worldwide suffers from metabolic syndrome, with a five times increased risk of type 2 diabetes and three times likelihood of having a heart attack and stroke. ${ }^{4}$ There is a growing interest to understand common mechanisms associated with metabolic and mental health disorders due to their rising prevalence in both developed and developing nations. Diabetes has been associated with depression while their combination may negatively affect both diabetes associated secondary complications and depressive conditions thus aggravating both the disorders. It has been reported that diabetic individuals especially with poor glycemic control are at a 2-3 times higher risk of developing depression than their nondiabetic counterparts with about 30\% diabetic patients experiencing depressive episodes..$^{5-7}$ Again depression and obesity seem to have a circular relation-
Submission Date: 18-04-2017; Revision Date: 13-07-2017; Accepted Date: 27-10-2017

DOI: 10.5530/ijper.51.4s.94 Correspondence: Dr Sugato Banerjee,

Department of Pharmaceutical Sciences and Technology Birla Institute of Technology, Mesra, Ranchi: 835215, INDIA.

Phone no: 91-651-2275444

Fax no: 91-651-2275290

Email Id: sbanerjee@

bitmesra.ac.in

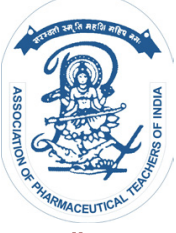

www.ijper.org 
ship, both flaming each other. ${ }^{8,9}$ While depression may increase the risk of obesity by $58 \%$; obese individuals are $55 \%$ more likely to suffer from one or other form of depression. ${ }^{9}$ Many of these studies blame central obesity as the cornerstone for developing depression ${ }^{10}$ while inflammation, advanced glycation end products (AGEs) and reduced brain derived neurotrophic factor (BDNF) levels during obesity has been the primary suspects in inducing obesity induced depression. Obesity may elicit an inflammatory response, ${ }^{11}$ elevating key inflammatory cytokines like tumor necrosis factor- $\alpha$ (TNF- $\alpha$ ), interferons and certain interleukins like IL-6 and 8, all have been believed to be involved in mood disorders. Increased levels of IL-6 have been directly associated with MDD. ${ }^{12,13}$ On the other hand BDNF has been shown to play an important role in schizophrenia, ${ }^{14,15}$ depression, anxiety, ${ }^{16}$ along with obesity. ${ }^{17} \mathrm{BDNF}$ deficient animals which are phenotypically obese ${ }^{18}$ may also display increased aggression and hyperactivity. ${ }^{19}$ Elevated advanced glycation end products may also lead to depression in type 1 diabetic animals due to impaired hippocampal neurogenesis. ${ }^{20,21}$

Usually, MetS individuals suffer from both obesity and type 2 diabetes. Various clinical studies have co-related $\mathrm{MetS}$ with depression and depressive symptoms, irrespective of gender, obesity status and type 2 diabetes. ${ }^{22,23}$ MetS has been linked with depression through functions of HPA axis. Loss of Glucocorticoid receptors may alter hypothalamus-pituitary-adrenal (HPA)-axis regulation. ${ }^{24} \mathrm{HPA}$ axis may play a major role in the pathogenesis of MetS. ${ }^{25}$ Obese individuals may exhibit elevated plasma cortisol. ${ }^{26}$ On the other hand, higher evening cortisol level has been observed in patients suffering from a major depressive disorder. However further studies are needed to characterize other pathways leading to depression in MetS individuals. There is also a lack of suitable antidepressants for the treatment of depression in MetS individuals. ${ }^{27}$ Understanding the neuropath genesis of MetS-associated depression as well as the screening of novel antidepressants warrants an urgent need to develop a suitable animal model. Models of MetS which may spontaneously develop signs of depression, mimicking the human form of the disease. Here we use high fat and 20\% fructose diet to develop MetS in swiss albino mice which after 4 weeks developed the typical characteristics of MetS including fasting blood glucose, insulin resistance, hypertriglyceridemia, hyperlipidemia, central obesity, and hypertension. We then characterized the development of depressive disorder these animals. We further evaluated the role of various neurotransmitters which may be responsible for MetS associated depression in these animals.

\section{MATERIALS AND METHODS}

Normal pallet, Maize starch, Lard, cassien, vitamin and mineral mixture and sodium chloride were purchased from VRK nutritional solutions, Pune, India. Casein (Charotar casein company, Baroda, India) fructose (Loba chemie Pvt. Ltd, Mumbai India), diazepam and gabapentin (Sun Pharma Industries Ltd, Mumbai India) phenobarbitone (Piramal Health Care, Mumbai India) hydroxyzine (Uni-med India, Mumbai, India) and fluoxetine, bupropione (Cipla Ltd, Mumbai, India). Triglyceride, total cholesterol and high-density lipid were measured using respective kits (Coral Clinical system, Goa, India).

\section{Experimental Groups}

Swiss Albino male outbred mice (18-22 g) were used for the study. Initially, the animals were housed in colony cages and maintained under standard environmental conditions at $25^{\circ} \mathrm{C}, 12: 12 \mathrm{~h}$ light: dark cycle, and $50-55 \%$ relative humidity, with free access to food and water ad libitum. The institutional animal ethical committee approved the protocol (GCTS/IAEC/2013-SEPT/08) for the study.

Groups (10 animals/ group)

i. Control group animals were fed with standard diet kept in normal condition.

ii Depression group animals were subjected to inescapable stress by foot shock

iii Metabolic syndrome group was on High fat diet supplemented with $20 \%$

Fructose solution for 4 weeks. High fat diet constituted Maize starch $367 \mathrm{~g} / \mathrm{kg}$, Lard $316 \mathrm{~g} / \mathrm{kg}$, Casein $255 \mathrm{~g} / \mathrm{kg}$, Vitamin mineral mix $61 \mathrm{~g} / \mathrm{kg}$ and Sodium chloride $1 \mathrm{~g} / \mathrm{kg}$. Drinking water was supplemented with $20 \%$ fructose solution

\section{Assessment of Metabolic Syndrome}

Changes in food intake, the weight of the animal, waist circumference, systolic blood pressure, fasting blood glucose and lipid profile were assessed for the animals.

\section{Fasting blood glucose}

Animals fasted overnight. Fasting blood glucose was measured by tail prick method using one touch glucose strips (Bayer India Ltd).

\section{Lipid profile}

After four weeks of HFHC diet, the mice were fasted overnight and anesthetized using ketamine, and cardiac puncture collected blood samples were used to measure total cholesterol (TC), HDL, triglyceride (TG) in plasma. 
Low-density lipid (LDL) were calculated using the formula $\mathrm{LDL}=\mathrm{TC}-\mathrm{HDL}-\mathrm{TG} / 5.0(\mathrm{mg} / \mathrm{dL}){ }^{28}$

\section{Blood pressure}

Non-invasive blood pressure system (IITC Life Sciences. USA) was used to measure systolic and diastolic blood pressure.

\section{Behavioral Evaluation}

\section{Inescapable foot shock induced Depression}

The foot-shock chamber consists of a wooden box with a metallic grid floor. The grids are connected to the shock generator. The depression group of mice were placed in the box and received 60 inescapable foot shocks daily ( $0.8 \mathrm{~mA}$ for $15 \mathrm{sec}$ at $45 \mathrm{sec}$ intervals) with randomized starting time any time of the day during 30 to 60 min session to add to the unpredictability of the procedure. A light flash of $15 \mathrm{sec}$ preceded each shock as a psychological stressor. Each animal in this group received 60 foot-shocks daily for first 20 days while in the next 20 days they received foot-shocks on alternate days. On the last day, the shock exposed rats were subjected to only light stimulus without the shock..$^{29,30}$

\section{Forced swim test}

Mice were forced to swim in a vertical glass cylinder (height: $40 \mathrm{~cm}$; diameter: $18 \mathrm{~cm}$, containing $15 \mathrm{~cm}$ of water at $20-25^{\circ} \mathrm{C}$ ). Time taken by each animal to become immobile was measured. Animals showing comparable immobility time were used for further experiments. The total duration of immobility was measured during a 5-min test. An animal was judged to be immobile whenever it remained floating passively in the water in a slightly hunched but upright position, its nose just above the surface. ${ }^{31,32}$

\section{Tail Suspension Test}

The mice were suspended by their tail using the test apparatus and immobility was recorded for $5 \mathrm{~min}$. Animals were considered immobile when they hang passively and motionless for at least $1 \mathrm{~min}$. The animals in different groups were suspended and observed for the time taken to become immobile. . $^{32,33}$

\section{Biochemical Estimation \\ Estimation of gamma amino butyric acid}

Brain tissue was homogenized in $5 \mathrm{~mL}$ of $0.01 \mathrm{M} \mathrm{HCl}$. In this homogenate, $8 \mathrm{~mL}$ of ice cold ethanol was added and kept for $1 \mathrm{~h}$ at $0^{\circ} \mathrm{C}$. The contents were centrifuged for $10 \mathrm{~min}$ at $16,000 \mathrm{rpm}$ and the supernatant was collected in a petri dish. The precipitate was washed three times with $5 \mathrm{~mL}$ of $75 \%$ ethanol. The washes were combined with supernatant and evaporated to dryness. To the dry mass, $1 \mathrm{~mL}$ water and $2 \mathrm{~mL}$ chloroform were added and centrifuged at $2000 \mathrm{rpm}$. Upper phase containing GABA was separated, and $10 \mu \mathrm{L}$ of it was applied as spot on Whatman filter paper. The mobile phase consisted of $n$-butanol, acetic acid, and water in 4:1:5 ratios. The chamber was saturated for half an hour with mobile phase. The paper chromatogram was developed with ascending technique. The paper was dried in a hot air oven and then sprayed with $0.5 \%$ ninhydrin solution in $95 \%$ ethanol. The paper was dried. Blue spot developed on paper, which was cut and heated with $2 \mathrm{~mL}$ ninhydrin solution on a water bath at $60-65^{\circ} \mathrm{C}$. Water was added to the solution and kept for $1 \mathrm{~h}$ and supernatant was used. Absorbance was measured at $570 \mathrm{~nm}$ on a UV-visible spectrophotometer. ${ }^{34}$

\section{Estimation of Serotonin, Norepinephrine, and Dopamine}

The tissue (cortico-hippocampus) was homogenized in $0.1 \mathrm{ml} \mathrm{HCl}$-butanol for $1 \mathrm{~min}$ in a glass homogenizer made from a small centrifuge tube. The sample was then centrifuged for $10 \mathrm{~min}$ at $2000 \mathrm{~g}$. An aliquot of the supernatant phase was removed and added to an Eppendorf tube $(1.5 \mathrm{ml})$ containing $0.2 \mathrm{ml}$ heptanes (for spectroscopy) and $0.025 \mathrm{ml} \mathrm{HCl} 0.1 \mathrm{M}$. After $10 \mathrm{~min}$ of vigorous shaking, the tube was centrifuged under the same conditions as above in order to separate the two phases, and the overlying organic phase was discarded. The aqueous phase was then taken for 5-HT. For the preparation of standard 5-HT was mixed to dilution of $1000 \mu \mathrm{g} / \mathrm{ml}$ as the free base, with $0.1 \mathrm{~N}$ hydrochloric acid. To the samples $0.5 \mathrm{ml} 6 \mathrm{~N} \mathrm{HCl}$ was added and its fluorescence was read at $295 / 535 \mathrm{~nm}$. For Norepinephrine (NE) and dopamine estimation $0.02 \mathrm{ml}$ of the $\mathrm{HCl}$, $0.005 \mathrm{ml} 0.4 \mathrm{M} \mathrm{HCl}$ and $0.01 \mathrm{ml}$ EDTA sodium acetate buffer ( $\mathrm{pH}$ 6.9) were added, followed by $0.01 \mathrm{ml}$ iodine solution ( $0.1 \mathrm{M}$ in ethanol). The reaction was stopped after 2 min by addition of $0.01 \mathrm{ml} \mathrm{Na}_{2} \mathrm{SO}_{3}$ in $5 \mathrm{M}$ $\mathrm{NaOH}\left(0.5 \mathrm{~g} \mathrm{Na}_{2} \mathrm{SO}_{3}\right.$ in $2 \mathrm{ml}$ water $\left.+18 \mathrm{ml} 5 \mathrm{M} \mathrm{NaOH}\right)$. Acetic acid $(0.01 \mathrm{ml}, 10 \mathrm{M})$ was added $15 \mathrm{~min}$ later. The solution was then heated to $100^{\circ}$ for $6 \mathrm{~min}$. When the sample again reached room temperature, excitation and emission spectra were read at 395/485 $\mathrm{nm}$ for NE and $330 / 375$ for dopamine. Standards were prepared by adding $10 \mathrm{ng} \mathrm{NE}$ and $20 \mathrm{ng}$ dopamine in $0.005 \mathrm{ml}$ distilled water to $0.1 \mathrm{ml} \mathrm{HCl}$-butanol. ${ }^{35}$

\section{Statistical analysis}

The data were represented as mean \pm SEM. The difference between groups was calculated by one way ANOVA followed by Tukey's multiple comparison test. Probability values less than $0.05(P<0.05)$ were considered statistically significant. All statistical tests were conducted 
Table 1: Characterization of HFHC diet induced metabolic syndrome

\begin{tabular}{|c|c|c|}
\hline \multicolumn{2}{|c|}{ metabolic syndrome } \\
\hline & Control & $\begin{array}{c}\text { Metabolic } \\
\text { syndrome }\end{array}$ \\
\hline Body weight $(\mathrm{gm})$ & $21 \pm 1.1$ & $32.2 \pm 0.9^{* *}$ \\
\hline Waist circumference $(\mathrm{cm})$ & $7.2 \pm 0.9$ & $8.9 \pm 0.88^{* * *}$ \\
\hline Fasting blood glucose $(\mathrm{mg} / \mathrm{dl})$ & $112 \pm 2.5$ & $268 \pm 2.8^{* * *}$ \\
\hline Systolic blood pressure $(\mathrm{mm} \mathrm{Hg})$ & $112.2 \pm 2.2$ & $135 \pm 1.2^{* *}$ \\
\hline LDL $(\mathrm{mg} / \mathrm{dl})$ & $30 \pm 0.6$ & $86.5 \pm 2.1^{* * *}$ \\
\hline Triglyceride $(\mathrm{mg} / \mathrm{dl})$ & $107 \pm 2.6$ & $152.3 \pm 1.8^{* *}$ \\
\hline HDL $(\mathrm{mg} / \mathrm{dl})$ & $52.7 \pm 1.5$ & $42.7 \pm 2.1^{*}$ \\
\hline
\end{tabular}

All values are expressed as Mean \pm SEM. $(\mathrm{n}=10) * p<0.05 * * p<0.01 * * * p<0.001$

using Graph Pad Prism 4.0 software (GraphPad Software, Inc, San Diego CA).

\section{RESULTS}

High fat high carbohydrate diet (HFHC diet) led to significant increase in body weight $(p<0.01)$ and waist circumference $(p<0.01)$ compared to normal pallet diet. Other diagnostic characteristics of $\mathrm{Met}^{36,37}$ including fasting blood glucose levels $(p<0.01)$, systolic blood pressures $(p<0.01)$, lipid profile (increase in LDL $(p<0.001)$ and triglyceride $(p<0.01)$ and reduction in HDL levels $(p<0.05)$ were all significantly altered after 4 weeks in HFHC fed animals compared to their control counterparts. Thus suggesting that mice on HFHC diet developed signs of MetS. (Table 1).

Next, we measured depression levels in these animals. To access depression levels in HFHC diet fed animals forced swim and tail suspension tests were performed. Inescapable chronic foot shock was administered to induce depression, to a group of animals serving as depression control. For forced swim and tail suspension tests the total immobility time was measured. Chronic foot shock stress induced (depression) and MetS animals showed comparable immobility time suggesting the development of depression in both the groups. Both stress induced animals and MetS animals showed significant $(p<0.001)$ increase in immobility time over normal controls in forced swim test. A similar observation was recorded in tail suspension test where depression group showed maximum immobility followed by MetS group. Both the groups showing a significant increase in immobility $(p<0.001$ and $p<0.01$ respectively) over normal controls (Figure 1A and B). The above results suggest the development of depression in HFHC diet induced MetS animals.

Most of the antidepressants are monoamine reuptake inhibitors thus showing their antidepressant action by increasing the concentration of respective monoamines in the synapse, ${ }^{38}$ hence we measured levels of certain monoamines like 5-HT and NE in cortico-hippocampal lysates. MetS animals showed a significant decrease in NE $(p<0.01)$ levels compared to animals on a normal diet. The levels of NE in MetS animals was comparable to foot shock mediated depression group which showed a cortico-hippocampal decrease in both NE and 5-HT levels. However, corticohippocampal GABA and Dopamine levels remained unaltered in all the groups (data not shown). The above results show the role of NE in MetS associated depression. (Figure 1C and D) We also investigated the role of antidepressants, primarily acting on serotonergic, dopaminergic or adrenergic neurotransmitters in the reversal of MetS associated depression using forced swim and tail suspension tests. Nortryptaline, a NE reuptake inhibitor showed a dose dependent decrease in immobility time in MetS animals $(p<0.001)$ in both forced swim and tail suspension tests thus successfully reversing MetS induced depression. However, amitriptyline a serotonin and NE reuptake inhibitor with a higher preference towards serotonin re-uptake was unable to reverse signs of depression $(p>0.05)$ in MetS animals. Fluoxetine an established and serotonin reuptake inhibitor (SSRI) and bupropion which may prevent both dopamine and norepinephrine reuptake with a higher efficacy towards blocking dopamine reuptake were also unable to improve depression like symptoms ( $p>0.05$ ) in MetS animals. (Figure 2A and B)
A

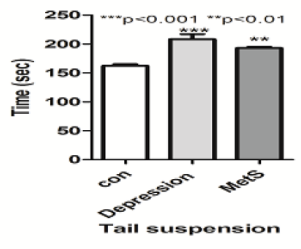

$c$

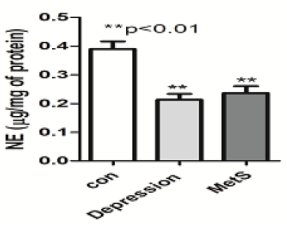

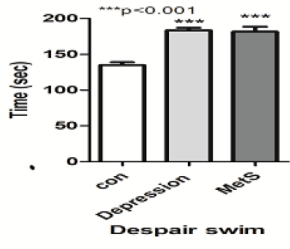

$\mathbf{D}$

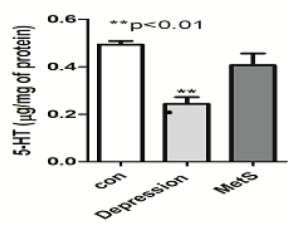

Figure 1: Effect of metabolic syndrome on depression

A) MetS and depression induced animals showed significant increase in immobility time ( $p<0.01$ and $p<0.001$ respectively) over control animals using tail suspension test.

B) MetS and depression induced animals showed significant increase in immobility time $(p<0.001)$ over control animals using forced swim test.

C) MetS and depression induced animals showed significant decrease in cortico-hippocampal NE levels $(p<0.01)$ compared to controls.

D) Depression induced animals showed significant decrease in cortico-hippocampal 5-HT levels over control and MetS animals. All values are expressed as Mean \pm SEM. $(n=10){ }^{*} p<0.05$ ${ }^{\star *} p<0.01{ }^{* * *} p<0.001$ 
A

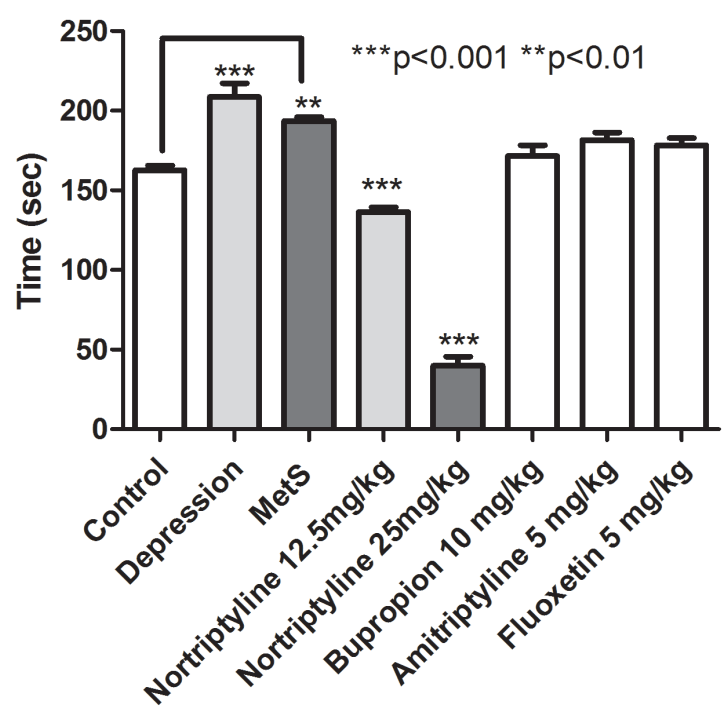

Tail suspension test

B

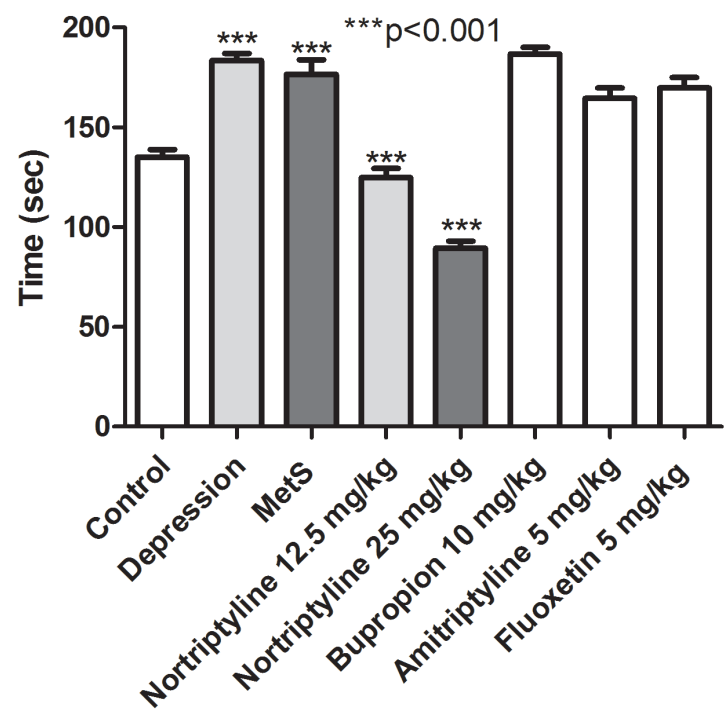

Forced swim test

Figure 2: Effect of monoamine uptake inhibitors in MetS associated depression

A) Nortriptyline showed a dose dependent decrease in immobility time in MetS animals $(p<0.001)$ while bupropione, amitryptaline and fluoxitine failed to reverse MetS associated depression using tail suspension test.

B) Nortriptyline showed a dose dependent decrease in immobility time in MetS animals $(p<0.001)$ while bupropione, amitryptaline and fluoxitine failed to reverse MetS associated depression using forced swim test.All values are expressed as Mean \pm SEM. $(\mathrm{n}=10) * p<0.05 * * p<0.01$ $* * * p<0.001$
The above results suggest that MetS associated depression may be primarily mediated by NE, independent of serotonergic or dopaminergic systems.

\section{DISCUSSION}

In the present study, we successfully induced metabolic syndrome using a high-fat diet with $20 \%$ fructose water in swiss albino mice. The animals developed the diagnostic characteristics of metabolic syndrome including high fasting blood glucose and glucose tolerance, hypertriglyceridemia and hypercholesteremia, central obesity, as well as increased body weight, food intake, and hypertension. Both epidemiological and animal studies have shown obesity to be a risk factor for mood disorders including depression. ${ }^{24-39}$ Diabetic rats have also been shown to develop signs of depression. ${ }^{40,41}$ However, how obesity or diabetes may lead to depression is not very well characterized. Here we used HFHC diet to induce MetS in mice. These animals spontaneously developed clear signs of depression comparable to animals subjected to electric foot shock induced depression which is based on the principle of learned helplessness. ${ }^{42}$ The Learned Helplessness paradigm uses a stress-exposure period in which animals are subjected to inescapable stress (electrical foot shock) in one or more sessions. Animals previously exposed to inescapable stress show reduced abilities to escape in this model. The reduced ability to escape is restored by different forms of antidepressant treatment. ${ }^{43}$ These helpless animals may exhibit behavioral similarly with human subjects suffering from depression. ${ }^{44}$ Two classical features are a lack of pleasure or anhedonia and lack of energy or anergia, both of which can be reversed by antidepressants. ${ }^{45} \mathrm{MetS}$ animals showed clear signs of depression with increased immobility time in both forced swim and tail suspension test comparable with inescapable foot shock induced depressed animals. Functional deficiency in 5-HT has been shown to be the primary biochemical change in depression in both human and animals. ${ }^{46,47}$ Animal models of type 2 diabetes associated depression also shows similar characteristics. ${ }^{48}$ The effect of NE on diabetes associated depression is far from being clear. Some studies, have reported a change in NE concentration in both depressed and diabetic animals. ${ }^{46,49,50}$ Paschos et al. reported up-regulated of $\mathrm{NE}$ in the peripheral nervous system, and downregulation in the hippocampal region at times of depression. ${ }^{51}$ Ferraro et al. reported an increase in plasma NE in patients with type 1 diabetes. ${ }^{52,53}$ While others have reported a decrease in thalamic NE in diabetic animals subjected to stress. In MetS associated depressed animals we saw 
a significant reduction in cortico-hippocampal NE levels with little change in the 5-HT and dopamine levels. However, foot shock induced depressed animals showed decrease in both cortico-hippocampal NE and 5-HT levels. Others have reported insulin combined with clonazepam, or taurine may reverse type 1 diabetes associated depression suggesting the role GABA. ${ }^{41}$ However, MetS animals showed little change in cortico-hippocampal GABA levels when compared to normal controls (data not shown). Next, we tried reversing MetS induced depression using anti-depressants, primarily acting on serotonergic, dopaminergic or adrenergic systems. Nortryptaline, a potent NE reuptake inhibitor could successfully reverse the MetS associated depression by reducing the tail suspension and forced swim latency. While amitriptyline which is serotonin and NE reuptake inhibitor with a higher potency towards serotonin were unable to reverse signs of depression in these animals. Serotonin reuptake inhibitor fluoxetine and dopamine reuptake inhibitor bupropion were also unable to improve the mental conditions of MetS animals. The above results clearly show the role of $\mathrm{NE}$ in diet induced MetS associated mice model of depression. Some of the popular antidepressants like citalopram and fluoxetine have been reported to be ineffective in cases of obesity related depression ${ }^{54}$ adding to the challenges of antidepressant therapy for obese and MetS individuals. Thus, the antidepressant potential of compounds which primarily targets the adrenergic systems may be tested on depressed individuals suffering from metabolic disorders.

\section{CONCLUSION}

In the current study we successfully developed a costeffective non-transgenic MetS associated depression model using Swiss albino mice. We further show decreased cortico-hippocampal NE levels in these animals with little change in the levels of 5-HT, dopamine, and GABA. The MetS associated depression was successfully reversed by nortryptaline an established NE reuptake inhibitor, thus confirming the role of $\mathrm{NE}$ in MetS associated depression in these animals.

\section{ACKNOWLEDGEMENT}

Thanks are due to Prof Late Debesh Chandra Majumdar chairman Trinity trust and all the faculty members of Gupta College of Technological Sciences Asansol, for their constant support and encouragement. We are also thankful to Dr. BN Sinha professor and Head Department of Pharmaceutical Sciences and Technology, BIT, Mesra for his support.

\section{CONFLICT OF INTEREST}

No conflict of interest are declared.

\section{ABBREVIATION USED}

MetS: Metabolic syndrome; HFHC: High fat high carbohydrate; MDD: Major depressive disorder; LDL: Low density lipoprotein; HDL: High density lipoprotein; GABA: Gama-Aminobutyric acid; NE: Norepinephrine 5-HT-5 hyroxytryptamine; AGEs: Advanced glycation end products; BDNF: Brain derived neurotrophic factor.

\section{REFERENCES}

1. Kessler RC, Berglund P, Demler O, Jin R, Koretz D, Merikangas KR, Rush AJ, Walters EE, Wang PS. The epidemiology of major depressive disorder: results from the National Comorbidity Survey Replication. J. Am. Med. Assoc. 2003;289(23):3095-105.

2. Rush AJ, Trivedi MH, Wisniewski SR, Niereberg AA, Stewart JW, Warden D, Niederehe G, Thase ME, Lavori PW, Lebowitz BD, McGrath PJ, Rosenbaum JF, Sackeim HA, Kupfer DJ, Luther J, Fava M. Acute and longer-term outcomes in depressed outpatients requiring one or several treatment steps: a STAR*D report. Am. J. Psychiatry. 2006;163(11):1905-17.

3. Grundy SM, Brewer HB, Cleeman, JI, Smith SC. and Lenfant C. Definition of MetS report of the National Heart, Lung, and Blood Institute/American Heart Association Conference on scientific issues related to definition. Circulation 2004;109(3):433-38.

4. Zimmet P, Alberti KGM, Kaufman F, Tajima N, Silink M, Arslanian S, Wong G, Bennett $P$, Shaw J, and Caprio $S$. The metabolic syndrome in children and adolescents-an IDF consensus report. Pediatric diabetes 2007;8(5):299-06.

5. Anderson RJ, Freedland KE, Clouse RE, Lustman PJ. The prevalence of comorbid depression in adults with diabetes: A meta-analysis. Diabetes Care 2001;24(6):1069-78.

6. Judd LL, Rapaport MH, Paulus MP, Brown JL. Subsyndromal symptomatic depression: A new mood disorder? J Clin Psychiatry 1994;55 Suppl:18-28.

7. Lustman PJ, Freedland KE, Carney RM, Hong BA, Clouse RE. Similarity of depression in diabetic and psychiatric patients. Psychosom Med. 1992;54:602-11.

8. Shelton RC, Miller AH. Eating ourselves to death (and despair): the contribution of adiposity and inflammation to depression. Prog Neurobiol. 2010;91(4):275-99.

9. Luppino FS, de Wit LM, Bouvy PF, Stijnen T, Cuijpers P, Penninx BW, et al. Overweight, obesity, and depression: a systematic review and meta-analysis of longitudinal studies. Arch Gen Psychiatry. 2010;67(3):220-9.

10. Kyrou I, Chrousos GP, Tsigos C: Stress, visceral obesity, and metabolic complications. Ann N Y Acad Sci 2006;1083(1):77-110.

11. Deng T, Lyon CJ, Minze LJ, Lin J, Zou J, Liu JZ, et al. Class II Major Histocompatibility Complex Plays an Essential Role in Obesity- Induced Adipose Inflammation. Cell Metab. 2013;17(3):411-22.

12. Sasayama D, Hattori K, Wakabayashi C, Teraishi T, Hori H, Ota M, et al. Increased cerebrospinal fluid interleukin-6 levels in patients with schizophrenia and those with major depressive disorder. J Psychiatr Res. 2013;47(3):401-6.

13. Alesci S, Martinez PE, Kelkar S, llias I, Ronsaville DS, Listwak SJ, et al. Major depression is associated with significant diurnal elevations in plasma interleukin-6 levels, a shift of its circadian rhythm, and loss of physiological complexity in its secretion: clinical implications. J Clin Endocrinol Metab. 2005; 90(5):2522-30.

14. Li W, Zhou N, Yu Q, Li X, Yu Y, Sun S, Kou C, Chen DC, Xiu MH, Kosten TR, Zhang XY. Association of BDNF gene polymorphisms with schizophrenia and clinical symptoms in a Chinese population. Am J Med Genet B Neuropsychiatr Genet. 2013;162B(6):538-45. 
15. Favalli G, Li J, Belmonte-de-Abreu P, Wong AH, Daskalakis ZJ. The role of BDNF in the pathophysiology and treatment of schizophrenia. J Psychiatr Res. 2012;46(1):1-11.

16. Sun MM, Yang LM, Wang Y, Feng X, Cui KY, Liu LF, et al. BDNF Val66Met polymorphism and anxiety/depression symptoms in schizophrenia in a Chinese Han population. Psychiatr Genet. 2013;23(3):124-9.

17. Gray J, Yeo GS, Cox JJ, Morton J, Adlam AL, Keogh JM, et al. Hyperphagia, severe obesity, impaired cognitive function, and hyperactivity associated with functional loss of one copy of the brain-derived neurotrophic factor (BDNF) gene. Diabetes. 2006;55(12):3366-71.

18. Sha H, Xu J, Tang J, Ding J, Gong J, Ge X, Kong D, Gao X. Disruption of a novel regulatory locus results in decreased Bdnf expression, obesity, and type 2 diabetes in mice. Physiol Genomics. 2007;31(2):252-63.

19. Coppola V, Tessarollo L. Control of hyperphagia prevents obesity in BDNF heterozygous mice. Neuroreport. 2004;15(17):2665-68.

20. Yamagishi S, Nakamura K, Matsui T. Agents that block advanced glycation end product (AGE)-RAGE (receptor for AGEs)-oxidative stress system: a novel therapeutic strategy for diabetic vascular complications. Expert Opin Investig Drugs. 2008;17(7):983-96.

21. Wang S, Sun Z, Guo Y, Yuan Y, Yang B. Diabetes impairs hippocampal function via advanced glycation end product mediated new neuron generation in animals with diabetesrelated depression. Toxicol Sci. 2009;111(1):72-9.

22. Skilton MR, Moulin P, Terra JL, Bonnet F. Associations between anxiety, depression, and the metabolic syndrome. Biol Psychiat. 2007;62:1251-57.

23. Takeuchi T, Nakao M, Nomura K, Inoue M, Tsurugano S, Shinozaki $Y$, Yano E. Association of the metabolic syndrome with depression and anxiety in Japanese men: a 1-year cohort study. Diabetes Metab Res Rev. 2009;25(8):762-67.

24. Kurhe Y, Mahesh R. Pioglitazone, a PPARY agonist rescues depression associated with obesity using chronic unpredictable mild stress model in experimental mice. Neurobiology of Stress. 2016;18;3:114-21.

25. Nousena EK, Franco JG, and Sullivan EL. Unraveling the mechanisms responsible for the comorbidity between metabolic syndrome and mental health disorders. Neuroendocrinology. 2013;98(4):254-66.

26. Bjorntorp P. Endocrine abnormalities of obesity. Metabolism. 1995; 44(Suppl 3):21-3.

27. Deuschle M. Effects of antidepressants on glucose metabolism and diabetes mellitus type 2 in adults. Curr Opin Psychiatry. 2013;26(1):60-5.

28. Tremblay AJ, Morrissette H, Gagné JM, Bergeron J, Gagné C, Couture P. Validation of the Friedewald formula for the determination of low-density lipoprotein cholesterol compared with $\beta$-quantification in a large population. Clinical biochemistry. 2004;37(9);785-90.

29. Lin Y, Westenbroek C, Bakker P, Termeer J, Liu A, Li X, Ter Horst GJ. Effects of long-term stress and recovery on the prefrontal cortex and dentate gyrus in male and female rats. Cereb cortex. 2008;18(12):2762-74.

30. Banerjee R, Hazra S, Kumar S, Ghosh AK, Mondal AC. Behavioral consequences of chronic stress and effects of antidepressant treatment on animal models of depression. AJPN. 2013;1(1):5-13.

31. Kaster MP, Raupp I, Binfaré RW, Andreatini R, Rodrigues ALS, Antidepressant like effect of lamotrigine in themouse forced swimming test: evidence for the involvement of the noradrenergic system, Eur. J. Pharmacol. 2007;565(1):119-24.

32. Saha S, Banerjee S. Central Nervous System Stimulant actions of Alpinia galanga (L.) rhizome: A preliminary study. Indian J Exp Biol. 2013;51:828-32.

33. Steru L, Chermat $R$, Thierry $B$, Simon $P$, The tail suspension test: a new method for screening antidepressants in mice. Psychopharmacology.1985;85(3):367-70.

34. Bansal P, Banerjee S. Effect of withinia somnifera and shilajit on alcohol addiction in mice. Phcog Mag. 2016;12:S121-8.
35. Schlumpf M, Litchsteiger W, Langemann H, Waser PG, Hefti F. Fluorimetric micromethod for simultaneous determination of serotonin, noradrenaline and dopamine in milligram amounts of brain tissue. Biochemical Pharmacology. 1974;23,2337-46.

36. Sun SS, Grave GD, Siervogel RM, Pickoff AA, Arslanian SS, and Daniels SR. Systolic blood pressure in childhood predicts hypertension and metabolic syndrome later in life. Pediatrics. 2007;119(2):237-46.

37. Bozkurt B, Aguilar D, Deswal A, Dunbar SB, Francis GS, Horwich T, et al. Contributory Risk and Management of Comorbidities of Hypertension, Obesity, Diabetes Mellitus, Hyperlipidemia, and Metabolic Syndrome in Chronic Heart Failure: A Scientific Statement from the American Heart Association. Circulation. 2016; 134(23):535-78.

38. Belmaker RH, Agam G. Major depressive disorder. N Engl J Med. 2008;358(1):55-68.

39. Simon GE, Von-Korff M, Saunders K, Miglioretti DL, Crane PK, van Belle G, Kessler RC. 2006. Association between obesity and psychiatric disorders in the US adult population. Arch. Gen. Psychiatry. 2006;63(7):824-30.

40. Li H, Zuo YM, Zuo YH, Lei YH, Xu RJ, Wang Y. Modeling of Diabetes MellitusRelated Depression. Neurophysiology. 2014;46(1):71-8.

41. Wayhs CAY, Tortato C, Mescka CP, Sitta A, Ribas GS, Guerreiro G, et al. Central and Peripheral Taurine Levels in Diabetic Rats under DepressiveLike Behavior Treated with Insulin and/or Clonazepam. Austin Diabetes Res. 2016;1(1):1004.

42. Catharine H. Duman. Models of Depression. Hormones of the Limbic System Vol.82. Vitamins and Hormones. Elsevier Science and Technology. 2010:2-15.

43. Anisman $\mathrm{H}$, Matheson K. Stress, depression, and anhedonia: Caveats concerning animal models. Neurosci Biobehav Rev. 2005;29(4-5):525-46.

44. Maier SF. Learned helplessness and animal models of depression. Prog. Neuropsychopharmacol. Biol. Psychiatry.1984;8(3):435-46.

45. Lin Y, Westenbroek C, Bakker P, Termeer J, Liu A, Li X, Ter Horst GJ. Effects of long-term stress and recovery on the prefrontal cortex and dentate gyrus in male and female rats. Cereb cortex. 2008;18(12):2762-74.

46. Heninger GR, Charney DS. Monoamine receptor systems and anxiety disorders, Psychiat. Clin. North Am. 1988;11:309-26.

47. $\mathrm{Hu} \mathrm{D}, \mathrm{Gu} \mathrm{H}$, Xiong Y. Changes and significance of orphanin $F Q$ and monoamine neurotransmitters in patients with postpartum depression. Chin J Nerv Ment Dis. 2003;29:321-22.

48. Miyata S, Hirano S, Kamei J. Diabetes attenuates the antidepressantlike effect mediated by the activation of $5-\mathrm{HT} 1 \mathrm{~A}$ receptor in the mouse tail suspension test. Neuropsychopharma. 2004;29(3):461-69.

49. Scholl JL, Renner KJ, Forster GL, Tejani-Butt S. Central monoamine levels differ between rat strains used in studies of depressive behavior, Brain Res. 2010;1355: 41-51.

50. Vasquez PA, Salmi P, Ahlenius S, Mathé AA. Neuropeptide $Y$ in brains of the Flinders Sensitive Line rat, a model of depression. Effects of electroconvulsive stimuli and d-amphetamine on peptide concentrations and locomotion. Behavioural brain research. 2000;111(1):115-23.

51. Paschos KA, Veletza S, Chatzaki E. Neuropeptide and sigma receptors as novel therapeutic targets for the pharmacotherapy of depression. CNS Drugs. 2009;23:(9)755-72.

52. Ferraro S, Perrone-Filardi P. Maddalena G, Desiderio A, Gravina E, Turco S, Chiariello M. Comparison of left ventricular function in insulinand non-insulindependent diabetes mellitus. Am. J. Cardiol. 1993;71(5):409-14.

53. Ferraro S, Fazio S, Santomauro M, Cianfrani M, Mossetti G, Turco S, et al. Cardiac function and sympathetic activity in young diabetics, Diab. Res. Clin. Pract. 1990;8(2):91-9.

54. Isingrini E, Camus V, Guisquet AM, Pingaud M, Devers S, Belzung C. Association between repeated unpredictable chronic mild stress (UCMS) procedures with a high fat diet: a model of fluoxietine resistance in mice. Plos One. 2010; 5: e10404. 


\section{PICTORIAL ABSTRACT}

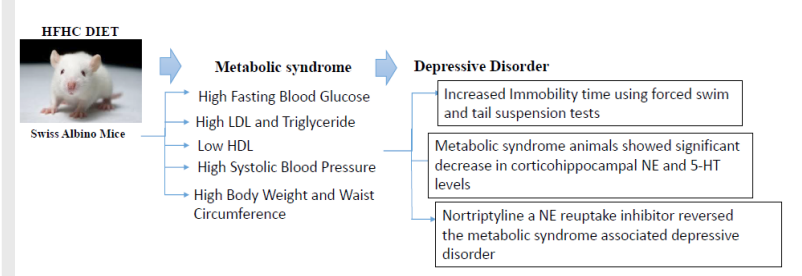

\section{SUMMARY}

A non-transgenic diet induced animal model of metabolic syndrome was developed and characterised. The model closely reflects the characteristics of human form of metabolic syndrome disorder. These metabolic syndrome animals spontaneously developed signs of depressive disorder. Norepinephrine was found to be the primary neurotransmitter responsible for MetS associated depression in these animals.

\section{About Authors}

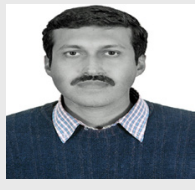

Dr. Sugato Banerjee: Is working as Assistant Professor in the Department of Pharmaceutical Sciences and Technology, BIT Mesra, Ranchi, India. He has published more than 30 peer-reviewed research articles in international journals. He is an editorial board member of Pharmacognosy Magazine. His primary research area is to study secondary complications and their underlying mechanisms associated with metabolic disorders using non-transgenic murine models.

Cite this article: Mukherjee A, Sen KK and Banerjee S. Effect of Metabolic Syndrome on Depression in Mice. Indian $\mathrm{J}$ of Pharmaceutical Education and Research. 2017;51(4S):S645-S52. 